\title{
BMJ Open Socioeconomic status, remoteness and tracking of nutritional status from childhood to adulthood in an Australian Aboriginal Birth Cohort: the ABC study
}

\author{
Pauline Sjöholm (D , , ${ }^{1,2}$ Katja Pahkala, ${ }^{3,4}$ Belinda Davison, ${ }^{5}$ Markus Juonala,,${ }^{1,6}$ \\ Gurmeet Singh ${ }^{5,7}$
}

To cite: Sjöholm P, Pahkala K, Davison B, et al. Socioeconomic status, remoteness and tracking of nutritional status from childhood to adulthood in an Australian Aboriginal Birth Cohort: the $\mathrm{ABC}$ study. BMJ Open 2020;10:e033631. doi:10.1136/ bmjopen-2019-033631

- Prepublication history and additional material for this paper are available online. To view these files, please visit the journal online (http://dx.doi. org/10.1136/bmjopen-2019033631).

Received 14 August 2019 Revised 08 January 2020 Accepted 09 January 2020

Check for updates

(C) Author(s) (or their employer(s)) 2020. Re-use permitted under CC BY-NC. No commercial re-use. See rights and permissions. Published by BMJ.

For numbered affiliations see end of article.

Correspondence to Dr Pauline Sjöholm; plsjoh@utu.fi

\section{ABSTRACT}

Objectives To determine prevalences of underweight and overweight as well as low and high waist-to-height ratio (WHtR) in three prospective follow-ups and to explore tracking of these measures of nutritional status from childhood to adolescence and adulthood. The influence of socioeconomic status, remoteness, maternal body mass index (BMI) and birth weight on weight status was assessed.

Design Longitudinal birth cohort study of Indigenous Australians.

Setting Data derived from three follow-ups of the Aboriginal Birth Cohort study with mean ages of $11.4,18.2$ and 25.4 years for the participants.

Participants of the 686 Indigenous babies recruited to the study between 1987 and 1990, 315 had anthropometric measurements for all three follow-ups and were included in this study.

Primary and secondary outcome measures BMI categories (underweight, normal weight, overweight and obesity),WHtR categories (low and high), sex, areal socioeconomic disadvantage as defined by the Indigenous Relative Socioeconomic Outcomes index, urban/remote residence, maternal BMI and birth weight. Logistic regression was used to calculate 0 Rs for belonging to a certain BMI category in adolescence and adulthood according to BMI category in childhood and adolescence.

Results Underweight was common (38\% in childhood and $24 \%$ in adulthood) and the prevalence of overweight/obesity increased with age (12\% in childhood and $35 \%$ in adulthood). Both extremes of weight status as well as low and high WHtR tracked from childhood to adulthood. Underweight was more common and overweight was less common in remote and more disadvantaged areas. Birth weight and maternal BMI were associated with later weight status. There were significant sex differences for prevalences and tracking of WHtR but not for BMI.

Conclusions Socioeconomic factors, remoteness and gender must be addressed when assessing nutritionrelated issues in the Indigenous communities due to the variation in nutritional status and its behaviour over time within the Indigenous population.

\section{Strengths and limitations of this study}

- This cohort is the longest running and largest Indigenous birth cohort in Australasia and presents unique data about the health of the contemporary Indigenous population.

- Despite logistic challenges relating to geography and accessibility, the retention rates were good.

- The present study offers novel findings about the geographical, socioeconomic and gender differences in nutritional status that should be addressed when developing new strategies to reduce the immense health inequalities in Australia.

- The study population was relatively small with a substantial amount of missing data.

- At this young age, the participants are healthy with very few showing overt disease, thus analysis of morbidity was not done. This will be addressed in future follow-ups.

\section{INTRODUCTION}

The dual burden of malnutrition defined as the coexistence of obesity and underweight within individuals, households or populations is a phenomenon commonly seen in low-income and middle-income countries but less so in high-income countries. ${ }^{1}$

The Indigenous (used respectfully to include both Aboriginal and Torres Strait Islander peoples) population in Australia has experienced a dramatic nutritional transition since European colonisation. ${ }^{2}$ Indigenous Australians, especially those living in remote regions, are prone to a number of morbidities associated with non-favourable nutrition throughout life. ${ }^{3}$ In 2012-2013, Indigenous Australians were 1.5 times as likely to be affected by obesity as non-Indigenous Australians, with $30 \%$ of Indigenous children aged 2-14 years and $66 \%$ of persons aged 15 years and over being affected by overweight or obesity. ${ }^{4}$ However, underweight was almost twice as common in childhood: 
$8 \%$ of Indigenous children were underweight compared with $4.8 \%$ of non-Indigenous children. ${ }^{5}$ Obesity is a welldocumented risk factor for cardiovascular disease, type 2 diabetes, cancer and several other non-communicable diseases ${ }^{67}$ while underweight, a possible manifestation of malnutrition and nutritional deficiencies, ${ }^{8}$ is also associated with raised infection risk $^{9}$ and pregnancy complications. ${ }^{10}$ Both extremes of body composition are associated with substantial medical costs for the communities involved. ${ }^{11}$ Overweight and obesity tend to 'track' from childhood to adulthood, that is, remain relatively stable throughout an individual's life course, according to studies conducted in non-Indigenous populations. ${ }^{12}$ Tracking of underweight is a topic less studied but has been reported in some cohorts. ${ }^{13}$ There is a paucity of data in Indigenous children and adolescents regarding tracking of nutritional status.

In high-income countries, low socioeconomic status has been shown to be associated with obesity. ${ }^{14}$ However, in low-income and middle-income countries, the association is often reversed, and persons of higher socioeconomic status are more likely to be affected by obesity. ${ }^{15}$ The effects of socioeconomic factors and remoteness on nutritional status have generally been similar for the Indigenous and the non-Indigenous Australians with obesity being concentrated in urban and less disadvantaged areas. ${ }^{416}$ To our knowledge, there have been no studies examining the longitudinal development of nutritional status and its associations with socioeconomic factors in very remote regions of Australia, where food insecurity is high ${ }^{17}$ and malnutrition and underweight are more common. $^{18}$

The Aboriginal Birth Cohort (ABC) was formed to better understand the reasons behind the high burden of disease of the Australian Indigenous population and identify possibilities for early prevention. To date, the study is one of the longest running and largest Indigenous birth cohorts in Australasia. The intention of this paper is: (1) to explore tracking of nutritional status from childhood to adulthood and (2) to explore the association of socioeconomic status and remoteness at birth with later nutritional status in the cohort.

\section{METHODS}

\section{Participants}

Details of the recruitment and follow-up of the ABC have been previously published in detail. ${ }^{19}{ }^{20}$ In brief, between 1987 and 1990, 686 of the eligible 1238 babies born to Indigenous mothers at the Royal Darwin Hospital were recruited into the study. There were no differences for mean birth weights or sex ratios between those recruited and those not recruited. Since recruitment (wave 1), three follow-ups have been conducted: in childhood (wave 2$)$ at a mean age of 11.4 years $(n=572 ; 86 \%$ of living participants), in adolescence (wave 3) at a mean age of 18.2 years $(\mathrm{n}=469 ; 71 \%$ of living participants $)$ and most recently in early adulthood (wave 4 ) at a mean age of 25.4 years ( $\mathrm{n}=459 ; 71 \%$ of living participants).

All procedures contributing to this work comply with the Helsinki Declaration of 1975, as revised in 2008. All participants provided written informed consent to participate in this study.

\section{Patient and public involvement}

The study has clear commitment to engaging with Indigenous communities and building Indigenous capacity. Indigenous researchers have been involved in all aspects of the study at each of the follow-ups including investigators, data collection team and local community members employed as research assistants, encouraging and facilitating formal research training. Extensive consultation with expert, Indigenous and cohort reference groups was conducted prior to each follow-up to obtain advice and guidance on contact methods, acceptability of planned procedures and methods of feedback to individuals and communities. Due to the difficulty in providing individual feedback after the initial visit, feedback is aimed at the community level in remote areas. Updates are published in community newsletters and in the national Aboriginal and Islander Health Worker Journal and provided to local community groups, stakeholders and governance groups.

\section{Anthropometric measurements}

At birth, maternal height and weight was recorded and used to calculate body mass index $\left(\mathrm{BMI} ; \mathrm{kg} / \mathrm{m}^{2}\right)$, which was classified as underweight $(<18.5)$, normal weight (18.5-24.99), overweight (25-29.99) or obese $(\geq 30)$. Birth weight of the participants was transformed into Z-scores and put into five categories based on the WHO child growth charts ${ }^{21}$ : (1) low: <-2; (2) low-normal: -2 to -1 ; (3) normal: -1 to 1 ; (4) normal-high: $1-2$; and (5) high: $>2$.

At each follow-up of the study, a small group (3-4) of trained researchers measured height and weight using standardised methods. Weight was measured in light clothing while barefoot to the last complete $0.1 \mathrm{~kg}$ with a digital scale (TBF-521; Tanita Corporation, Arlington Heights, Illinois, USA). Height was measured with a portable stadiometer to the nearest millimetre. BMI was calculated as weight $(\mathrm{kg})$ divided by height $(\mathrm{m})$ squared. Waist circumference was measured to the nearest millimetre using a flexible tape measure at the midpoint between the lowest rib and iliac crest at the end of exhalation.

Participants were categorised in classes of nutritional status using two alternative classifications: BMI, a widely used estimate for defining weight status and waist-toheight ratio $(\mathrm{WHtR})$, an alternative anthropometric measure to define adiposity.

For participants who had attained 18 years at follow-up, the following BMI categories were used: underweight: $<18.5$, normal weight: 18.5-24.99, overweight: 25-29.99, obese: $\geq 30$. For participants who were under 18 years of age at time of follow-up, age and sex specific cut-off points 
were used for categories of weight status (underweight, normal weight, overweight and obese) as defined by the International Obesity Task Force. ${ }^{22} 23$

WHtR has been suggested as a tool for better identifying abdominal obesity and delineating risk for cardiovascular disease and type 2 diabetes. ${ }^{24} \mathrm{~A}$ cut-off value of 0.5 for WHtR has been commonly used for screening for cardiometabolic risk irrespective of age, gender and ethnicity. ${ }^{25-27}$ There is no consensus on a lower normal limit for WHtR, but a value of less than 0.4 has also been previously used. WHtR was calculated as waist circumference in centimetres divided by height in centimetres and categorised as low $(<0.4)$, normal $(0.4-0.49)$ or high $(\geq 0.5) .{ }^{28}$

\section{Remoteness and childhood socioeconomic situation}

For areal socioeconomic disadvantage, the Indigenous Relative Socioeconomic Outcomes (IRSEO) index was used. The IRSEO is calculated at the Indigenous area level and is based on nine variables: three related to employment, three to education, two to housing and one to income, using information from the 2011 Census of Population and Housing. Each area is assigned to one of 100 percentiles, 1 for the most advantaged and 100 for the most disadvantaged. ${ }^{29}$ Based on their reported addresses at birth, the participants were assigned an IRSEO score. The scores were categorised into three groups: low disadvantage (1-40), mid-high disadvantage (range 41-90) and high disadvantage (range 91-100).

Area of residence was classified at birth, with families residing in a rural community with an Aboriginal council classified as 'remote' and all 'non-remote' locations were classified as 'urban'. At wave $4,18 \%$ of participants reported to have lived in another community at some point in their lives. However, limited movement between urban and remote settings was seen, with $8.7 \%$ of participants who had lived in a remote community at birth moving to an urban community by $4 \%$ and $19 \%$ of the participants who had lived in an urban community at wave 2 moving to a remote location at by wave 4 .

\section{Statistical analyses}

Participants who were pregnant at wave 3 and/or wave 4 were excluded from the analyses. Only participants who had height, weight and waist circumference recorded at all follow-ups were included $(n=315)$. Overweight and obesity were combined into one category due to small numbers. Attrition analyses were performed to compare baseline characteristics between participants included and not included at each follow-up with t-tests for continuous and $\chi^{2}$ tests for categorical variables. $\chi^{2}$ tests were used to assess the association of weight status and categories of remoteness, socioeconomic status, maternal BMI and birth weight at all follow-ups separately.

Tracking of nutritional status (underweight, overweight/obese and $\mathrm{WHtR}$, low and high) was analysed using logistic regression and reported as OR of status being constant across time: status in childhood continuing into adolescence and adulthood and status in adolescence continuing into adulthood. Regression analyses were adjusted for age at follow-up, sex and time between compared follow-ups as well as IRSEO category that was used as a proxy for socioeconomic status.

To assess the changes over time, Cochran's $Q$ tests and McNemar's tests were used to analyse the differences in the proportions of nutritional status categories by sex over the course of the three follow-ups.

Statistical tests were performed with SAS V.9.4. Statistical significance was inferred at a two-tailed $p$ value $<0.05$.

\section{RESULTS}

Complete data (height, weight and waist circumference) at all follow-ups were available on 315 participants. There were no significant differences in sex, birth weight and maternal BMI in participants included and those not included. There were significant differences between the two groups regarding remoteness and areal disadvantage: those included were more often from remote and more disadvantaged areas according to IRSEO scores (see online supplementary table 1 ). There were no significant differences between the BMI or the WHtR values at any follow-up between participants included and those not included (for BMI: $\mathrm{p}=0.48$ for wave 2 and $3, \mathrm{p}=0.47$ for wave 4; for WHtR: $\mathrm{p}=0.5,0.46$ and 0.52 , respectively). Descriptive statistics of the participants are presented in table 1 .

High rates of underweight were seen at all three follow-ups: $38.1 \%$ at wave $2,38.1 \%$ at wave 3 and $23.5 \%$ at wave 4 . Overweight and obesity increased over time: for overweight, $8.9 \%$ at wave $2,12.1 \%$ at wave 3 and $22.9 \%$ at wave 4 , and for obesity, $2.9 \%, 6.4 \%$ and $11.8 \%$, respectively. Prevalences of BMI categories according to sex are presented in figure 1. There were no significant differences between the sexes in the prevalence of underweight, overweight or obesity.

The differences in weight status over the course of the three follow-ups were significant with rates of underweight decreasing and rates of overweight/obesity rising $(p<0.0001$ for underweight and overweight/obesity for both sexes). There was no statistically significant difference in the rate of underweight between wave 2 and wave 3 ( $\mathrm{p}=0.56$ for men and $\mathrm{p}=0.76$ for women) but $\mathrm{a}$ significant difference in the prevalence of underweight between wave 2 and wave 4 ( $\mathrm{p}<0.0001$ for both sexes) as well as between wave 3 and wave $4(\mathrm{p}<0.0001$ for both sexes). For the prevalences of overweight/obesity, there was a statistically significant difference between wave 2 and wave 3 for male participants but not for women ( $p=0.002$ for men and $p=0.16$ for women). Between wave 2 and wave 4 , the difference was statistically significant for both sexes $(\mathrm{p}<0.0001)$ as well as between wave 3 and wave 4 ( $\mathrm{p}=0.0007$ for men and $\mathrm{p}<0.0001$ for women).

Prevalences of low $(<0.4)$ and high $(\geq 0.5)$ WHtR in the three follow-ups are presented in figure 2. There were no differences between the sexes at wave 2 . In 
Table 1 Descriptive characteristics

\section{Anthropometric characteristics of participants}

\begin{tabular}{|c|c|c|c|c|c|c|}
\hline & \multicolumn{2}{|c|}{ Childhood (wave 2) } & \multicolumn{2}{|c|}{ Adolescence (wave 3) } & \multicolumn{2}{|c|}{ Adulthood (wave 4) } \\
\hline & Male & Female & Male & Female & Male & Female \\
\hline Age, years $\pm S D$ & $11.1 \pm 1.1$ & $10.8 \pm 1.1$ & $17.9 \pm 1.1$ & $17.7 \pm 1.1$ & $25.4 \pm 1.1$ & $25.2 \pm 1.2$ \\
\hline Height, $\mathrm{cm}$ & $143.1 \pm 10.1$ & $143.0 \pm 10.5$ & $173.3 \pm 6.9$ & $161.3 \pm 5.2$ & $174.3 \pm 7.0$ & $161.4 \pm 5.6$ \\
\hline BMI & $16.4 \pm 3.5$ & $16.8 \pm 3.4$ & $21.2 \pm 5.6$ & $20.7 \pm 4.9$ & $23.3 \pm 6.0$ & $23.3 \pm 6.2$ \\
\hline WHtR & $0.45 \pm 0.05$ & $0.45 \pm 0.05$ & $0.45 \pm 0.08$ & $0.48 \pm 0.08$ & $0.49 \pm 0.09$ & $0.54 \pm 0.1$ \\
\hline
\end{tabular}

Mean values with SD for anthropometric measurements of participants in three follow-ups and baseline characteristics.

$\mathrm{BMI}$, body mass index; $\mathrm{WHtR}$, waist-to-height ratio.

\begin{tabular}{llll}
\hline Birth characteristics of participants & Male & Female & Total \\
\hline N & $158(50.2 \%)$ & $157(40.8 \%)$ & 315 \\
Urban residence, \% & 13.3 & 8.3 & $10.8(\mathrm{n}=315)$ \\
Birth weight, Zscore \pm SD & $-0.16 \pm 1.2$ & $-0.42 \pm 1.1$ & $-0.29 \pm 1.1(\mathrm{n}=293)$ \\
IRSEO score & $78.6 \pm 23.9$ & $83.0 \pm 19.7$ & $80.8 \pm 22.0(\mathrm{n}=315)$ \\
BMI of mother & $22.0 \pm 3.8$ & $22.6 \pm 4.4$ & $22.3 \pm 4.1(\mathrm{n}=236)$ \\
\hline
\end{tabular}

IRSEO, Indigenous Relative Socioeconomic Outcomes.

later follow-ups, male participants more often had a low WHtR $(22.2 \%$ vs $10.2 \%$ at wave $3(p=0.004)$ and $13.9 \%$ vs $5.1 \%$ at wave $4(\mathrm{p}=0.008))$, while female participants more often had a high WHtR $(34.4 \%$ vs $20.9 \%$ at wave 3 $(\mathrm{p}=0.007)$ and $58.6 \%$ vs $36.1 \%$ at wave $4(\mathrm{p}<0.0001))$. The changes in WHtR over the course of the three follow-ups were significant with rates of low WHtR decreasing and rates of high WHtR rising $(\mathrm{p}=0.002$ for men and $\mathrm{p}=0.03$ for women for low WHtR and $\mathrm{p}<0.0001$ for both sexes for high WHtR). Between wave 2 and wave 3 , there was a statistically significant difference between the rates for low WHtR for men $(p=0.003)$ but not for women $(p=0.4)$. Between wave 2 and wave 4 , the difference was significant for women $(p=0.01)$ but not for men $(p=0.4)$. For high

\section{Prevalences of weight classes by sex in three prospective} follow-ups

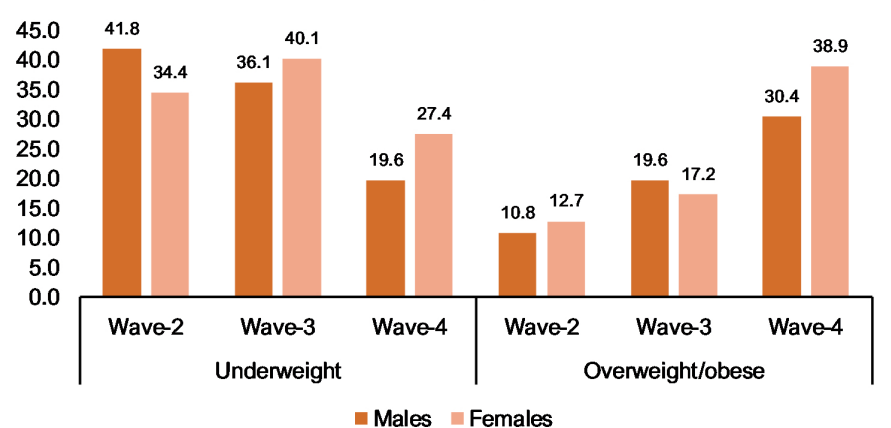

Figure 1 Percentages of underweight and overweight/ obese participants by sex. For classification, age and sex specific cut-off points were used for participants under 18 years of age at follow-up. For participants aged 18 years and over, underweight was classified as $\mathrm{BMI}<18.5$; normal weight as 18.5-24.99; overweight as 25-29.99; and obesity as $\geq 30$.
WHtR, the difference was significant between wave 2 and wave 3 ( $p=0.002$ for men and $p<0.0001$ for women) and between wave 2 and wave 4 ( $p<0.0001$ for both sexes).

The associations between weight class and remoteness, maternal BMI, areal disadvantage (IRSEO) and birth weight are presented in figure 3. Urban participants were significantly more likely to be overweight/obese and less likely to be underweight than remote participants in all follow-ups. Areal socioeconomic disadvantage was significantly associated with weight class in all follow-ups: participants from more disadvantaged areas were more often underweight and less often overweight/ obese than participants from less disadvantaged areas. Maternal weight status was significantly associated with offspring weight status in all follow-ups with children of

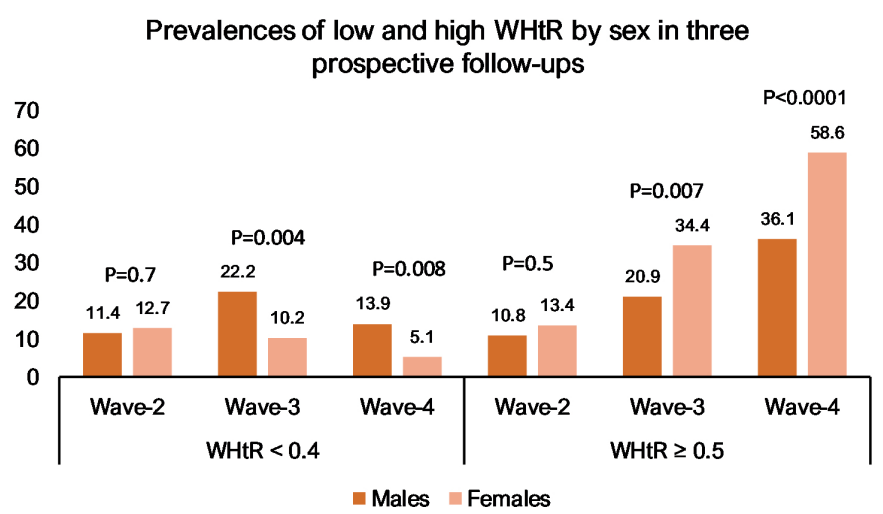

Figure 2 Prevalences for low and high waist-to-height ratio (WHtR) at three time points according to sex. $\mathrm{P}$ values were calculated with $\chi^{2}$ tests and represent differences between sexes. Values are in percentages. 

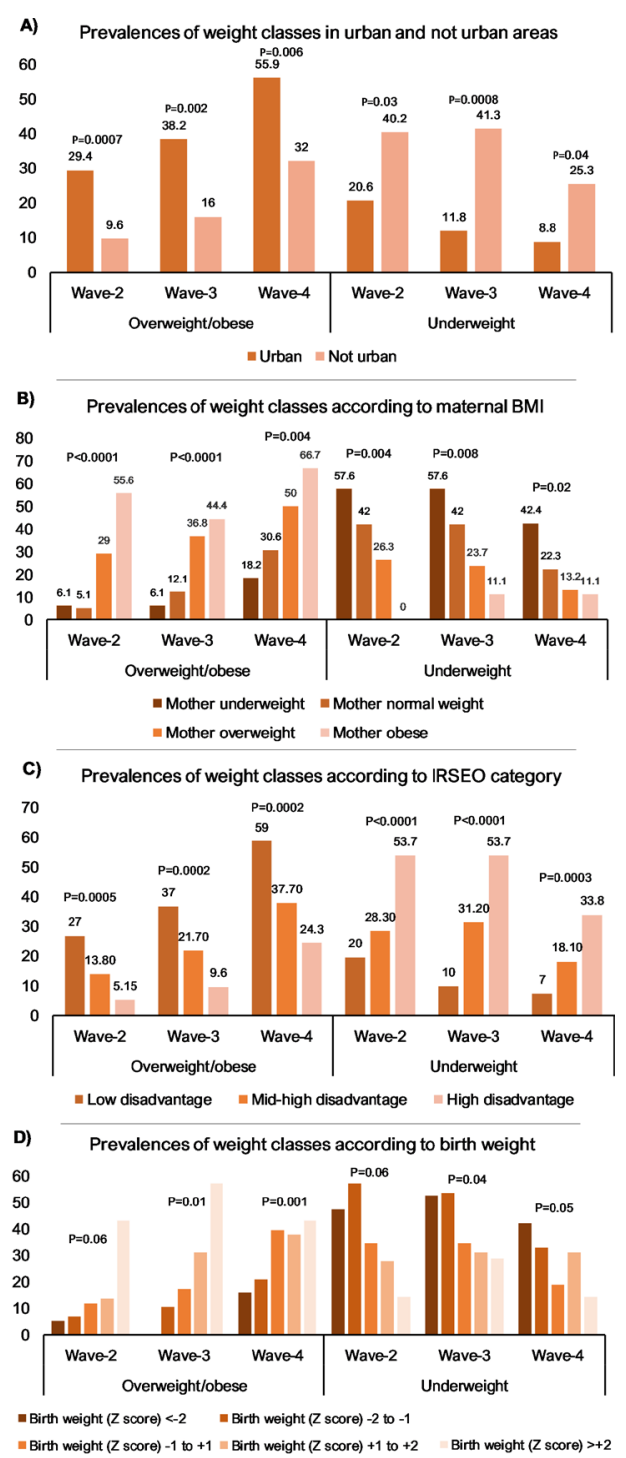

Figure 3 Prevalences of overweight/obesity and underweight in participants according to urban residence (A), maternal BMI (B), areal disadvantage (C) and birth weight (D). $\chi^{2}$ tests were used to assess association between weight status and presented categories.

underweight mothers being more often underweight and children of overweight and obese mothers more often presenting with overweight and obesity. Birth weight was also associated with later weight status: smaller babies were more often underweight and less often overweight or obese in all follow-ups. The association was significant in all follow-ups except for overweight status at wave 2 $(\mathrm{p}=0.06)$ and underweight status at wave $3(\mathrm{p}=0.06)$.

Analyses of tracking of weight status according to BMI categories are presented in table 2. Tracking was significant between age groups for all BMI categories, with sex not a significant confounder in any of the analyses. Of the participants who were overweight/obese at wave $2,67.6 \%$ remained in the same weight status category at wave 3 (OR $12.9, \mathrm{p}<0.0001)$ and $83.8 \%$ at wave 4 (OR 10.9, $\mathrm{p}<0.0001$ ). Of the participants who were overweight/obese at wave $3,86.2 \%$ continued to be overweight/obese at wave 4
(OR 21.3, $\mathrm{p}<0.0001$ ). Conversely, of the participants who were overweight/obese at wave 4 , only $28.4 \%$ had been overweight/obese already at wave $2 \%$ and $45.9 \%$ at wave 3. Underweight status also showed significant tracking throughout the follow-ups. Of the participants who were underweight at wave $2,76.7 \%$ were underweight at wave 3 (OR 22.6, p<0.0001) and 46.7\% remained underweight at wave 4 (OR 9.8, $\mathrm{p}<0.0001)$. Of underweight participants at wave $3,83.8 \%$ were underweight at wave 4 (OR 17.3, $\mathrm{p}<0.0001)$.

There was significant tracking of both low and high WHtR in all follow-ups. Sex was a significant confounder in most analyses (table 3 ) with tracking of low WHtR being more likely for male participants and tracking of high WHtR more likely for female participants. Of the participants who had a low WHtR at wave 2, 44.7\% remained in the same category at wave $3(\mathrm{OR} 8.5, \mathrm{p}<0.0001)$ and $23.7 \%$ at wave 4 (OR $4.7, p=0.003$ ), while $45.1 \%$ of participants with a low WHtR at wave 3 had a low WHtR at wave 4 (OR 21.3, $\mathrm{p}<0.0001)$. Of the participants with a high $\mathrm{WHtR}$ at wave $2,71.1 \%$ had a high WHtR at wave 3 (OR 8.3, $\mathrm{p}<0.0001$ ) and $94.7 \%$ at wave 4 (OR 25.0, $\mathrm{p}<0.0001$ ). Of the participants with a high WHtR at wave $3,85.1 \%$ remained in the same category at wave 4 (OR 10.3, $\mathrm{p}<0.0001)$. Of the participants who had a high WHtR in adulthood, 24.2\% had a high WHtR already in childhood and $49.7 \%$ in adolescence.

\section{Sensitivity analyses}

To test for bias due to the large amount of dropouts, sensitivity analyses were performed for tracking analyses for all plausible values for the whole cohort. Logistic regression analyses adjusted for sex, age at follow-up and time between follow-ups determined that tracking of overweight/obesity was significant from wave 2 to wave $3(\mathrm{p}<0.0001, \mathrm{OR}=17.3)$ and wave $4(\mathrm{p}<0.0001, \mathrm{OR}=16.1)$ as well as from wave 3 to wave $4(\mathrm{p}<0.0001, \mathrm{OR}=18.7)$. Tracking was also significant for underweight from wave 2 to wave $3(\mathrm{p}<0.0001, \mathrm{OR}=15.8)$ and to wave $4(\mathrm{p}=0.003$, $\mathrm{OR}=4.1)$ and from wave 3 to wave $4(\mathrm{p}<0.0001, \mathrm{OR}=11.2)$. High WHtR tracked from wave 2 to wave $3(\mathrm{p}<0.0001$, $\mathrm{OR}=9.9)$ and to wave $4(\mathrm{p}<0.0001, \mathrm{OR}=21.8)$ and from wave 3 to wave $4(p<0.0001, O R=7.9)$. Low WHtR tracked from wave 2 to wave $3(\mathrm{p}=0.002, \mathrm{OR}=2.6)$ and to wave 4 $(\mathrm{p}=0.005, \mathrm{OR}=2.4)$ and from wave 3 to wave $4(\mathrm{p}<0.0001$, $\mathrm{OR}=7.8$ ).

\section{DISCUSSION}

In this Indigenous cohort, underweight was common from childhood through to adolescence and young adulthood. Overweight/obesity was relatively less common but increased across time. This is in contrast to the general Australian Indigenous population, where rates of overweight and obesity are higher. It may reflect the cohort demographics with many people residing in remote and very remote communities. 


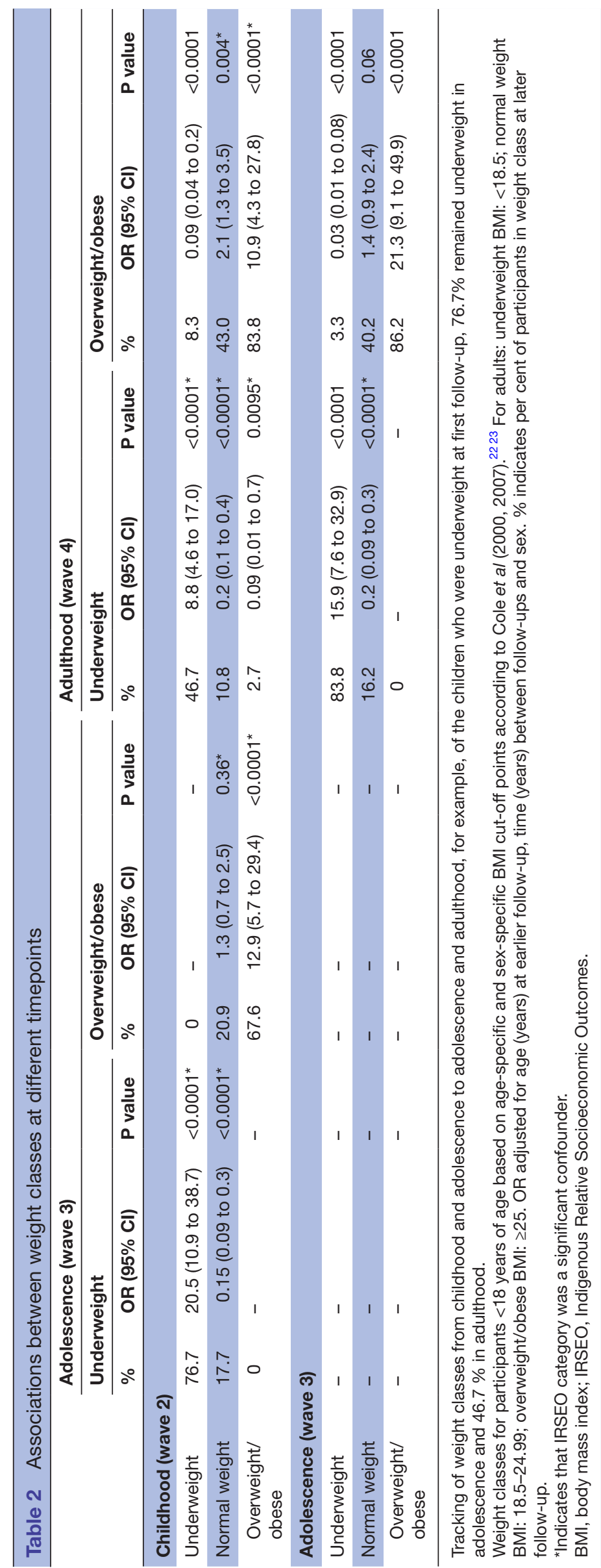

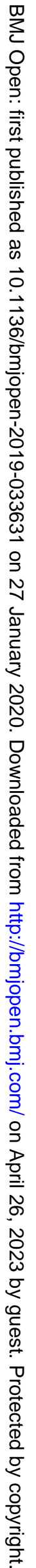


There is significant tracking of nutritional status from childhood to adulthood among Indigenous Australians in this cohort, both when assessed with BMI or WHtR categories. In contrast to BMI, there were significant differences between the sexes for both tracking and prevalence of WHtR categories with women more often presenting with central adiposity in adolescence and adulthood. This finding is consistent with previous studies that show that Indigenous women in general have greater waist circumference than their non-Indigenous counterparts. ${ }^{30} 31$

We have previously reported that women in this cohort have lower levels of physical activity, which may be a possible contributing factor. ${ }^{32}$ Central adiposity is a known risk factor for cardiovascular morbidity that accounts for a substantial part of the disparity in health outcomes between Indigenous and non-Indigenous Australians. Therefore, women seem to be at particular risk for chronic disease due to their body fat composition. ${ }^{31}$

Both areal disadvantage and remote residence were associated with lower prevalence of overweight/obesity and higher rates of underweight. This is in contrast to a study from New South Wales that examined Indigenous people aged 45 years and older, where participants from more advantaged and urban surroundings had lower prevalences of obesity and overweight than those from remote and disadvantaged areas. ${ }^{16}$ In a previous study from the $\mathrm{ABC}$, a significant association was found between remoteness and areal disadvantage at birth and longitudinal development of BMI measured at the same follow-ups as the present study. ${ }^{33}$ It seems that the spatial trend in obesity in this cohort is similar to that traditionally seen in low-income and middle-income countries, where obesity is more concentrated in cities and wealthier regions and underweight is more common in remote and rural settings. ${ }^{1}$ The dual burden of malnutrition within the population and the urban-remote differential in nutritional status has been previously described in the cohort at an average age of 25 years. ${ }^{34}$

The association between maternal BMI and offspring $\mathrm{BMI}$ is consistent with previous studies conducted in nonIndigenous cohorts. In the Generation $\mathrm{R}$ study, it was found that maternal obesity is associated with adverse cardiometabolic risk profiles including obesity, higher systolic blood pressure and adverse lipid levels in the offspring at the age of 6years. ${ }^{35}$ In the Avon Longitudinal Study of Parents and Children, a linear trend between maternal prepregnancy BMI and offspring adiposity levels was found: offspring of underweight mothers had lower rates and offspring of overweight mothers had higher rates of adiposity at 7.5 and 17.2 years. DNA methylation was suggested as a mediating factor. ${ }^{36}$

From a public health point of view, the present paper presents further evidence that dietary interventions need more tailored approaches, as there exist large variations within the Indigenous communities regarding nutritional status and its behaviour over time. Interventions need to be delivered within critical time windows and the gender perspective is essential: prepregnant women and girls in 
general should receive special attention. ${ }^{37}$ The reasons behind the dual burden of malnutrition, particularly the high rates of underweight in the remote and more disadvantaged communities, are multifactorial and include high food prices, low incomes, overcrowded households and rudimentary cooking facilities. ${ }^{38} 39$ Approaches that have been suggested to improve diet in the remote communities include eliminating socioeconomic constraints by reducing prices on fruits and vegetables in the community stores and enhancing nutrition-related consumer education and thus improving food security and self-efficacy to cook. ${ }^{40}$ Nutrition education including cooking skills workshops, group education sessions and store interventions have been reported to have some positive effect on obesity in Indigenous communities according to a review study that included both remote and urban communities in Australia. ${ }^{41}$ Multisector participatory approaches to strengthen food systems in remote Indigenous communities are needed ${ }^{42}$ with a special focus on nutrition in the early life.

The strengths of the study include its longitudinal design and well-structured follow-ups with relatively good retention rates. The study population however is relatively small causing some limitations to the interpretation of the results, and as only participants with data from all follow-ups were included, the missing data were quite substantial. However, the results from the sensitivity analyses where all data points were analysed were similar to the analyses presented. There were significant geographical differences between participants and nonparticipants, with non-participants being more often from urban and less disadvantaged areas. This potential bias may exaggerate the prevalences for underweight in the cohort as underweight was more prevalent in the remote and disadvantaged regions. The presented associations between weight status and socioeconomic status, remoteness, maternal BMI and birth weight are merely descriptive analyses presented separately for each follow-up as the data were not analysed in a longitudinal fashion and correlation over time was not assessed as this was not the main aim of the article. Other limitations include the definition of socioeconomic status, as the individual level indicators of socioeconomic status such as income were not available. IRSEO describes socioeconomic disadvantage on an area level and may not reflect the individual situation of the participants. Finally, the participants were still young during the last follow-up. After future follow-ups, cardiovascular morbidity and clinical events are likely to be more prevalent and could be analysed for even better understanding of the clinical relevance of the nutritional status and obesity trends in this cohort.

In summary, this study presents strong evidence on tracking of nutritional status from childhood to adulthood in this unique Indigenous cohort. Socioeconomic status and remoteness factors were associated with weight status in all follow-ups. The differences in central adiposity between men and women that seem to arise after childhood indicate a need for targeted and successfully timed approaches in dietary interventions. The high prevalence of underweight across all age groups requires special attention in the process of improving nutritional health overall in the remote Indigenous communities.

\section{Author affiliations}

${ }^{1}$ Department of Medicine, University of Turku, Turku, Finland

${ }^{2}$ Department of Anesthesiology, Vaasa Central Hospital, Vaasa, Finland

${ }^{3}$ Research Centre of Applied and Preventive Cardiovascular Medicine, University of Turku, Turku, Finland

${ }^{4}$ Paavo Nurmi Centre, Sports \& Exercise Medicine Unit, Department of Physical Activity and Health, University of Turku, Turku, Finland

${ }^{5}$ Menzies School of Health Research, Casuarina, Northern Territory, Australia

${ }^{6}$ Murdoch Childrens Research Institute, Parkville, Victoria, Australia

${ }^{7}$ Northern Territory Medical Program, Flinders University, Darwin, Northern Territory, Australia

Contributors All authors contributed to the analysis and interpretation of data. $\mathrm{BD}$ and GS were responsible for the design and implementation of the larger study of which this paper is a part. BD and GS collected and managed the data used in this study. PS wrote the paper with input from all authors. All authors approved of the final version to be submitted and agree to be accountable for all aspects of the work.

Funding The authors have not declared a specific grant for this research from any funding agency in the public, commercial or not-for-profit sectors.

\section{Competing interests None declared.}

Patient consent for publication Not required.

Ethics approval This study was approved by the Human Research Ethics Committee of Northern Territory Department of Health and Menzies School of Health Research, including the Aboriginal Ethical Subcommittee, which has the power of veto (ABC Reference no. 2013-2022). All research was performed in accordance with the National Health and Medical Research Council guidelines (National Statement on Ethical Conduct in Human Research, 2008). Informed written consent was obtained from all participants.

Provenance and peer review Not commissioned; externally peer reviewed.

Data availability statement Data may be obtained from a third party and are not publicly available. All data are stored confidentially and are not freely available in the public domain, but specific proposals for collaboration are welcomed. Collaborations are established through formal agreement with the $A B C$ steering committee. Contact information: abcstudy@menzies.edu.au.

Open access This is an open access article distributed in accordance with the Creative Commons Attribution Non Commercial (CC BY-NC 4.0) license, which permits others to distribute, remix, adapt, build upon this work non-commercially, and license their derivative works on different terms, provided the original work is properly cited, appropriate credit is given, any changes made indicated, and the use is non-commercial. See: http://creativecommons.org/licenses/by-nc/4.0/.

ORCID iD

Pauline Sjöholm http://orcid.org/0000-0002-3653-1466

\section{REFERENCES}

1 Popkin BM, Adair LS, Ng SW. Global nutrition transition and the pandemic of obesity in developing countries. Nutr Rev 2012;70:3-21.

2 Ferguson M, Brown C, Georga C, et al. Traditional food availability and consumption in remote Aboriginal communities in the Northern Territory, Australia. Aust N Z J Public Health 2017;41:294-8.

3 Brimblecombe JK, Ferguson MM, Liberato SC, et al. Characteristics of the community-level diet of Aboriginal people in remote northern Australia. Med J Aust 2013;198:380-4.

4 Australian Bureau of Statistics. Australian Aboriginal and Torres Strait Islander health survey: first results. Canberra: ABS, 2013.

5 AlHW. The health and welfare of Australia's Aboriginal and Torres Strait Islander peoples: 2015. Cat. no. IHW 147. Canberra: AlHW, 2015.

6 American College of Cardiology/American Heart Association Task Force on Practice Guidelines, Obesity Expert Panel, 2013. Executive summary: guidelines (2013) for the management of overweight and 
obesity in adults: a report of the American College of Cardiology/ American heart association Task force on practice guidelines and the obesity Society published by the obesity Society and American College of Cardiology/American heart association Task force on practice guidelines. based on a systematic review from the the obesity expert panel, 2013. Obesity 2014;22 Suppl 2:S5-39.

7 Franks PW, Hanson RL, Knowler WC, et al. Childhood obesity, other cardiovascular risk factors, and premature death. N Engl J Med 2010;362:485-93.

8 Cai W. Nutritional challenges for children in societies in transition Curr Opin Clin Nutr Metab Care 2014;17:278-84.

9 Dobner J, Kaser S. Body mass index and the risk of infection - from underweight to obesity. Clin Microbiol Infect 2018;24:24-8.

10 Cristina Rossi A. Underweight and pregnancy. BJOG 2016;123:2008.

11 Hoque ME, Mannan M, Long KZ, et al. Economic burden of underweight and overweight among adults in the Asia-Pacific region: a systematic review. Trop Med Int Health 2016;21:458-69.

12 Singh AS, Mulder C, Twisk JWR, et al. Tracking of childhood overweight into adulthood: a systematic review of the literature. Obes Rev 2008;9:474-88.

13 de Wilde JA, Middelkoop BJC, Verkerk PH. Tracking of thinness and overweight in children of Dutch, Turkish, Moroccan and South Asian descent from 3 through 15 years of age: a historical cohort study. Int J Obes 2018;42:1230-8.

14 Devaux M, Sassi F. Social inequalities in obesity and overweight in 11 OECD countries. Eur J Public Health 2013;23:464-9.

15 Dinsa GD, Goryakin Y, Fumagalli E, et al. Obesity and socioeconomic status in developing countries: a systematic review. Obes Rev 2012:13:1067-79.

16 Thurber KA, Joshy G, Korda R, et al. Obesity and its association with sociodemographic factors, health behaviours and health status among Aboriginal and non-Aboriginal adults in New South Wales, Australia. J Epidemiol Community Health 2018;72:491-8.

17 Australian Bureau of Statistics. Australian Aboriginal and Torres Strait Islander Health Survey: Nutrition Results - Food and Nutrients, 201213. Canberra: ABS, 2015.

18 Morris NF, Stewart S, Riley MD, et al. The burden and nature of malnutrition among patients in regional hospital settings: a crosssectional survey. Clin Nutr ESPEN 2018;23:1-9.

19 Sayers SM, Mackerras D, Singh G, et al. An Australian Aboriginal birth cohort: a unique resource for a life course study of an Indigenous population. A study protocol. BMC Int Health Hum Rights 2003;3:1.

20 Sayers S, Singh G, Mackerras D, et al. Australian Aboriginal birth cohort study: follow-up processes at 20 years. BMC Int Health Hum Rights 2009;9:23.

21 World Health Organization,. Who child growth standards.

22 Cole TJ, Bellizzi MC, Flegal KM, et al. Establishing a standard definition for child overweight and obesity worldwide: international survey. BMJ 2000;320:1240.

23 Cole TJ, Flegal KM, Nicholls D, et al. Body mass index cut offs to define thinness in children and adolescents: international survey. BMJ 2007:335:194.

24 Ashwell M, Gunn P, Gibson S. Waist-to-height ratio is a better screening tool than waist circumference and $\mathrm{BMI}$ for adult cardiometabolic risk factors: systematic review and meta-analysis. Obes Rev 2012;13:275-86.

25 Browning LM, Hsieh SD, Ashwell M. A systematic review of waist-toheight ratio as a screening tool for the prediction of cardiovascular disease and diabetes: 0.5 could be a suitable global boundary value. Nutr Res Rev 2010;23:247-69.

26 Khoury M, Manlhiot C, McCrindle BW. Role of the Waist/Height ratio in the cardiometabolic risk assessment of children classified by body mass index. J Am Coll Cardiol 2013;62:742-51.

27 Kuba VM, Leone C, Damiani D. Is waist-to-height ratio a useful indicator of cardio-metabolic risk in 6-10-year-old children? BMC Pediatr 2013;13:91.

28 Zhang Y-X, Wang Z-X, Chu Z-H, et al. Profiles of body mass index and the nutritional status among children and adolescents categorized by waist-to-height ratio cut-offs. Int $J$ Cardiol 2016;223:529-33.

29 Biddle N. CAEPR Indigenous population project: 2011 census papers. paper 13. socioeconomic outcomes. Canberra: Centre for Aboriginal Economic Policy Research, The Australian National University, 2013

30 Piers LS, Rowley KG, Soares MJ, et al. Relation of adiposity and body fat distribution to body mass index in Australians of Aboriginal and European ancestry. Eur J Clin Nutr 2003;57:956-63.

31 Adegbija OO, Wang Z. Gender variations in waist circumference levels between Aboriginal and non-Aboriginal Australian populations: a systematic review. Obes Res Clin Pract 2014;8:e513-24.

32 Sjöholm P, Pahkala K, Davison B, et al. Early life determinants of cardiovascular health in adulthood. The Australian Aboriginal birth cohort study. Int J Cardiol 2018;269:304-9.

33 Juonala M, Sjöholm P, Pahkala K, et al. The Australian Aboriginal birth cohort study: socio-economic status at birth and cardiovascular risk factors to 25 years of age. Med $J$ Aust 2019;211:265-70.

34 Davison B, Goodall J, Whalan S, et al. Nutritional dual burden in Indigenous young adults: the geographical differential. Aust J Rural Health 2019;27:14-21.

35 Gaillard R, Steegers EAP, Duijts L, et al. Childhood cardiometabolic outcomes of maternal obesity during pregnancy: the generation $\mathrm{R}$ study. Hypertension 2014;63:683-91.

36 Sharp GC, Lawlor DA, Richmond RC, et al. Maternal pre-pregnancy $\mathrm{BMI}$ and gestational weight gain, offspring DNA methylation and later offspring adiposity: findings from the Avon longitudinal study of parents and children. Int J Epidemiol 2015;44:1288-304.

37 Vaivada T, Gaffey MF, Das JK, et al. Evidence-Based interventions for improvement of maternal and child nutrition in low-income settings. Curr Opin Clin Nutr Metab Care 2017;20:204-10.

38 Ferguson M, O'Dea K, Chatfield M, et al. The comparative cost of food and beverages at remote Indigenous communities, Northern Territory, Australia. Aust N Z J Public Health 2016;40 Suppl 1:S21-6.

39 Pholeros P, Lea T, Rainow S, et al. Improving the state of health hardware in Australian Indigenous housing: building more houses is not the only answer. Int J Circumpolar Health 2013;72:21181.

40 Brimblecombe J, Ferguson M, Barzi F, et al. Mediators and moderators of nutrition intervention effects in remote Indigenous Australia. Br J Nutr 2018;119:1424-33.

41 Schembri L, Curran J, Collins L, et al. The effect of nutrition education on nutrition-related health outcomes of Aboriginal and Torres Strait Islander people: a systematic review. Aust N Z J Public Health 2016;40 Suppl 1:S42-7.

42 Brimblecombe J, Bailie R, van den Boogaard C, et al. Feasibility of a novel participatory multi-sector continuous improvement approach to enhance food security in remote Indigenous Australian communities. SSM Popul Health 2017;3:566-76. 